\title{
Prenatal ambient air pollution exposure and the risk of stillbirth: systematic review and meta-analysis of the empirical evidence
}

\author{
Nazeeba Siddika, ${ }^{1}$ Hamudat A Balogun, ${ }^{1}$ Adeladza K Amegah, ${ }^{1,2}$ \\ Jouni J K Jaakkola ${ }^{1,3}$
}

\begin{abstract}
- Additional material is published online only. To view please visit the journal online (http://dx.doi.org/10.1136/ oemed-2015-103086).

${ }^{1}$ Faculty of Medicine, Center for Environmental and Respiratory Health Research, University of Oulu, Oulu, Finland

${ }^{2}$ Department of Biomedical and Forensic Sciences,

University of Cape Coast, Cape Coast, Ghana

${ }^{3}$ Medical Research Center, University of Oulu and Oulu University Hospital, Oulu, Finland
\end{abstract}

Correspondence to Prof Jouni J K Jaakkola, Faculty of Medicine, Center for Environmental and Respiratory Health Research, Aapistie 5B, PO Box 5000, University of Oulu, Oulu 90014, Finland; jouni.jaakkola@oulu.fi

Received 21 May 2015 Revised 22 January 2016 Accepted 5 February 2016 Published Online First 24 May 2016

\section{SLinked}

- http://dx.doi.org/10.1136/ oemed-2016-103625

\section{CrossMark}

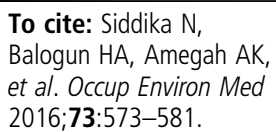

\begin{abstract}
Background Individual studies on the relations between ambient air pollution and the risk of stillbirth have provided contradictory results. We conducted a systematic review and meta-analysis to summarise the existing evidence.

Methods We conducted a systematic search of three databases: PubMed, Scopus and Web of Science, from their time of inception to mid-April, 2015. Original studies of any epidemiological design were included. Data from eligible studies were extracted by two investigators. To calculate the summary effect estimates (EE), the random effects model was used with their corresponding $95 \% \mathrm{Cl}$.
\end{abstract}

Results 13 studies met the inclusion criteria. Although not reaching statistical significance, all the summary effect estimates for the risk of stillbirth were systematically elevated in relation to mean prenatal exposure to $\mathrm{NO}_{2}$ per $10 \mathrm{ppb}(\mathrm{EE}=1.066,95 \% \mathrm{Cl} 0.965$ to $1.178, n=3), C O$ per 0.4 ppm $(E E=1.025,95 \% \mathrm{Cl}$ 0.985 to $1.066, \mathrm{n}=3), \mathrm{SO}_{2}$ per $3 \mathrm{ppb}(\mathrm{EE}=1.022,95 \%$ $\mathrm{Cl} 0.984$ to $1.062, \mathrm{n}=3$,), $\mathrm{PM}_{2.5}$ per $4 \mu \mathrm{g} / \mathrm{m}^{3}$ ( $E E=1.021,95 \% \mathrm{Cl} 0.996$ to $1.046, n=2)$ and $\mathrm{PM}_{10}$ per $10 \mu \mathrm{g} / \mathrm{m}^{3}$ ( $E E=1.014,95 \% \mathrm{Cl} 0.948$ to $1.085, \mathrm{n}=2$ ). The effect estimates for $\mathrm{SO}_{2}, \mathrm{CO}, \mathrm{PM}_{10}$ and $\mathrm{O}_{3}$ were highest for the third trimester exposure. Two time series studies used a lag term of not more than 6 days preceding stillbirth, and both found increased effect estimates for some pollutants.

Conclusions The body of evidence suggests that exposure to ambient air pollution increases the risk of stillbirth. Further studies are needed to strengthen the evidence.

\section{INTRODUCTION}

Ambient air pollution is a major environmental health problem in developed and in developing countries, ${ }^{1}$ and is a major cause of several important diseases including lung cancer, ${ }^{2}$ acute lower respiratory infections, ${ }^{3}$ cardiovascular diseases, ${ }^{4}$ pregnancy outcomes, ${ }^{5}$ chronic obstructive pulmonary disease $\mathrm{COPD}^{6}$ and asthma. ${ }^{7}$ The WHO reports that in $2012^{8}$ around 7 million people died -one in eight of total global deaths was as a result of air pollution exposure, 3.7 million of these were attributed to ambient air pollution due to exposure to particulate matter $\left(\mathrm{PM}_{10}\right) .{ }^{1}$ This estimate is more than twofold of the previous estimates and suggests that air pollution is now the world's largest single environmental health risk. ${ }^{1}$

Fetal growth and pregnancy outcome are determined by several factors including maternal

\section{What this paper adds}

- Previous reviews on the relations between prenatal exposure to air pollution and the risk of stillbirth were based on only three studies and were inconclusive. Emergence of a substantial number of studies since the last review, called for re-evaluation of the existing evidence.

- This systematic review and meta-analysis suggests an elevated risk of stillbirth in relation to air pollution, although further studies are needed to strengthen the evidence.

- Policies such as control of vehicular emissions, fuel quality improvement and control of industrial waste emission, should be developed and implemented to reduce the risk of air pollutants.

nutrition, environmental exposures and heredity. The prenatal stage of life is a very sensitive period such that exposure to harmful substances can have an adverse effect on the developing fetus. The effects of air pollution on fetal growth and pregnancy outcomes have been studied especially in developed countries and the results have been summarised in several reviews. ${ }^{9-12}$

The WHO reported that 2.6 million stillbirths occurred worldwide in 2009, according to the first comprehensive set of estimates published in a special series of Lancet, 2011. Every day, more than 7200 babies are stillborn. ${ }^{13}$ Previous studies have identified the important causes of stillbirth as umbilical cord accidents, congenital anomalies, placental abruption, maternal disease (diabetes, HIV, syphilis and hypertension), obesity, primiparity and smoking in pregnancy. ${ }^{14}$

Two previous reviews have suggested that ambient air pollutant exposure including nitrogen dioxide $\left(\mathrm{NO}_{2}\right)$, sulfur dioxide $\left(\mathrm{SO}_{2}\right)$, black carbon, carbon monoxide (CO), polycyclic aromatic hydrocarbons (PAH's) and particulate matter (PM), can also be an important cause of stillbirth, but both concluded that the evidence was weak at the time of conduct. There are also recent reviews indicating that air pollution from secondhand smoke ${ }^{15}$ and solid fuels ${ }^{16}$ increases the risk of stillbirth.

The two previous reviews of the effects of ambient air pollution evaluated three studies each, two of which were common to both reviews, with 
Glinianaia et $\mathrm{ll}^{17}$ stating that the evidence available is insufficient to assess a possible association between PM and stillbirth. Lacasana et $a l^{18}$ reported a positive but not consistent association between ambient air pollution and stillbirth; this may be due to an insufficient number of studies available. A recent review by $\mathrm{Zhu}$ et $a l^{19}$ evaluated the effect of exposure to $\mathrm{PM}_{2.5}$ on pregnancy outcomes but only included one study on stillbirth. A substantial number of studies have emerged since the conduct of these reviews, and this certainly calls for an evaluation of the evidence to provide insight into causality and identify gaps in knowledge. The objective of the present study was to assess the effect of prenatal ambient air pollution exposure on the risk of stillbirth through systematic review and meta-analysis.

\section{METHODS}

A systematic search of three databases-PubMed, Scopus and Web of Science-was carried out from their time of inception to mid-April, 2015, using Medical Subject Heading (MeSH) terms without any language restriction. The search terms used are listed in table 1.

Two investigators (NS and HAB) independently searched for relevant studies from the databases by first screening the titles of the citations and subsequently reviewing the abstracts of relevant titles. Studies selected after the abstract review were retrieved in full and reviewed with articles selected for inclusion in the study satisfying the following criteria: (1) original articles of any epidemiological design; (2) conducted in a human population; (3) provided effect estimates for the relation between exposure to any outdoor air pollutant and the risk of stillbirth, or reported the occurrence of stillbirth among exposed and unexposed mothers. The reference lists of the included studies were also reviewed to identify additional eligible studies.

\section{Data extraction and study quality appraisal}

A data extraction form adapted from our previous review ${ }^{16}$ was used independently by two investigators (NS and HAB) to extract the relevant information from the studies meeting the inclusion criteria. The information extracted by the two investigators was compared with any differences resolved by repeatedly checking the original articles and through discussion with the third investigator (AKA) adjudicating in situations where there were disagreements. Methodological quality of the

\section{Table 1 Search terms}

\begin{tabular}{|c|c|c|c|}
\hline $\begin{array}{l}\text { Exposure } \\
\text { MeSH Terms }\end{array}$ & $\begin{array}{l}\text { Free text } \\
\text { words }\end{array}$ & $\begin{array}{l}\text { Outcome } \\
\text { MeSH Terms }\end{array}$ & $\begin{array}{l}\text { Free text } \\
\text { words }\end{array}$ \\
\hline $\begin{array}{l}\text { Air pollution } \\
\text { Environmental pollution } \\
\text { Vehicular emission } \\
\text { Particulate matter } \\
\mathrm{PM} \\
\mathrm{Ozone} \\
\mathrm{O}_{3} \\
\mathrm{Nitrogen} \mathrm{dioxide}_{\mathrm{NO}_{2}} \\
\mathrm{Sulfur} \text { dioxide } \\
\mathrm{SO}_{2} \\
\mathrm{Carbon} \text { monoxide } \\
\mathrm{CO} \\
\text { Polycyclic aromatic } \\
\text { hydrocarbons } \\
\text { PAH }\end{array}$ & $\begin{array}{l}\text { Ambient air } \\
\text { pollution } \\
\text { Outdoor air } \\
\text { pollution } \\
\text { Ambient air } \\
\text { quality } \\
\text { Traffic exposure }\end{array}$ & $\begin{array}{l}\text { Stillbirth } \\
\text { Perinatal } \\
\text { mortality } \\
\text { Fetal mortality } \\
\text { Fetal death } \\
\text { Pregnancy } \\
\text { outcome }\end{array}$ & $\begin{array}{l}\text { Birth outcome } \\
\text { Intrauterine } \\
\text { mortality }\end{array}$ \\
\hline
\end{tabular}

included studies was assessed by investigating evidence of selection, information and confounding bias, and evaluation of the case ascertainment protocols. The general quality of the studies was assessed using the Newcastle-Ottawa Scale (NOS). ${ }^{20}$

\section{Statistical analysis}

Owing to differences in study design, geographical settings and different study population, we anticipated the inconsistency in the studies and applied the random effect model in summary effect estimates with their corresponding 95\% CI. Heterogeneity of the studies was assessed using the $\mathrm{I}^{2}$ statistic, with a value $>50 \%$ being deemed to indicate high heterogeneity, $25-50 \%$ indicating moderate and $<25 \%$ indicating low heterogeneity. Individual studies included in the meta-analysis had their effect estimates with different magnitude of air pollutant exposure (except for $\mathrm{NO}_{2}$ and $\mathrm{PM}_{10}$ ), therefore, before estimating the summary effects the individual effect estimates were converted with a common pollutant concentration such as per $3 \mathrm{ppb}$ increase in $\mathrm{SO}_{2}$, per $0.4 \mathrm{ppm}$ in $\mathrm{CO}, 4 \mu \mathrm{g} / \mathrm{m}^{3}$ in $\mathrm{PM}_{2.5}$ and $10 \mathrm{ppb}$ increase in $\mathrm{O}_{3}$ exposure. With regard to the study providing only trimester specific effect estimates, we first combined the three (1st, 2nd and 3rd trimester) estimates using the fixed effects model to get the estimate for the entire pregnancy, and then applied the combined estimate in the overall meta-analysis. Forest plots corresponding to each summary effect estimate were visually assessed. Sensitivity analysis was not conducted due to the small number of studies included in the meta-analysis. Publication bias was assessed by visual inspection of the funnel plots and application of Begg's and Egger's tests. Statistical analyses were performed using Stata V.13.0 (StataCorp LP, College Station, Texas, USA) software.

\section{RESULTS}

A total of 13 studies were included in the review. The study selection process is shown in figure 1.

\section{Characteristics of included studies}

The characteristics of the included studies are presented in online supplementary table S1.

Of the 13 studies, two studies ${ }^{21} 22$ assessed the effects of short-term air pollution exposure with the remaining studies focusing on long-term air pollution exposure. Six studies ${ }^{23-28}$ assessed maternal exposure to air pollution on a trimester basis.

Of the 11 epidemiological studies with assessment of longterm air pollution exposure, six studies ${ }^{23} 25-29$ employed a cohort design, of which one ${ }^{26}$ was prospective. Two studies ${ }^{30} 31$ were semiecological, that is, the exposure was assessed at group level and the outcome at individual level, and another two studies were cross-sectional ${ }^{32} 33$ with one study $^{24}$ applying a case control design. Of the two epidemiological studies with assessment of short-term air pollution exposure, one ${ }^{21}$ applied a case-crossover design with the hazard period defined as lag day 2 and reference periods selected by matching on the weekday within the same calendar month, and they also used two through 6 days before delivery as lag days. The other short-term air pollution exposure study ${ }^{22}$ was a time series analysis using Poisson regression and with lag effect of up to 5 days preceding delivery. Regarding the geographical location of the included studies, five studies were conducted in the USA, one in Latin America, three in East Asia, two in Europe, one in Russia and one in the UK. Seven of the included studies were published after the year 2005 .

Eleven $^{21-31}$ of the included studies relied on routine air monitoring data in their respective study areas in estimating maternal 
Figure 1 Flowchart of article selection process.

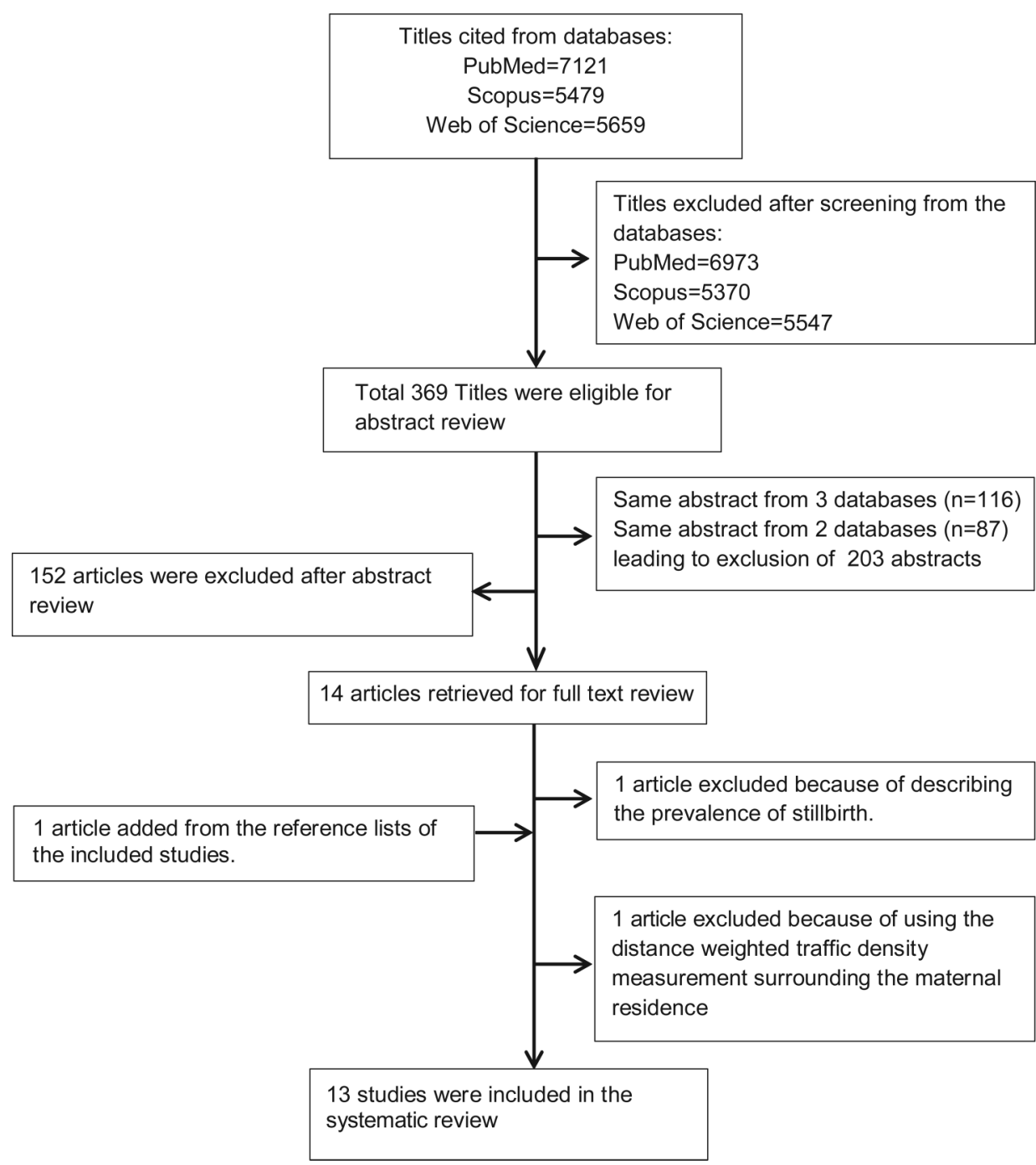

air pollution exposure. Landgren ${ }^{33}$ categorised each exposure in two ways, (1) above and below the mean exposure value $\left(\mathrm{SO}_{2}\right.$ : $8.0 \mu \mathrm{g} / \mathrm{g}, \mathrm{CH}: 6.6 \mu \mathrm{g} / \mathrm{g}$ and NO: $14.7 \mu \mathrm{g} / \mathrm{g}$ ) of all the included municipalities and (2) the municipality with the highest exposure level was compared with all other municipalities. Vassilev et $a l^{32}$ used statewide combined modelled average concentrations for each census tract and categorised exposures into low $\left(0.040-0.268 \mathrm{mg} / \mathrm{m}^{3}\right)$, medium $\left(0.269-0.610 \mathrm{mg} / \mathrm{m}^{3}\right)$ and high exposure $\left(0.611-2.830 \mathrm{mg} / \mathrm{m}^{3}\right)$ level with low exposure serving as the reference in the analysis. The included studies measured 13 pollutants including $\mathrm{SO}_{2}, \mathrm{NO}_{2}, \mathrm{CO}$, particles $\left(\mathrm{PM}_{2.5}, \mathrm{PM}_{10}\right.$, $\mathrm{SPM}), \mathrm{O}_{3}, \mathrm{NO}, \mathrm{POM}, \mathrm{NO}_{\mathrm{x}}$, hydrocarbon $(\mathrm{CH})$, black smoke, which was taken as equivalent to $\mathrm{PM}_{4}$ in the study that measured this pollutant, ${ }^{25}$ and suspended solids.

Of the 11 studies relying on air monitoring station data, seven studies ${ }^{21} 23-28$ and that by Vassilev et al $^{32}$ assigned exposures to mothers based on their residential addresses at the time of delivery. Regarding the studies conducted by Faiz et $a l^{21} 23$ and DeFranco et al, ${ }^{27}$ mothers had to live within a $10 \mathrm{~km}$ radius of the closest monitoring station; and Green et al ${ }^{28}$ used $20 \mathrm{~km}$ radius for $\mathrm{PM}_{2.5}, \mathrm{O}_{3}, \mathrm{SO}_{2}$ and $5 \mathrm{~km}$ radius for $\mathrm{CO}$ and $\mathrm{NO}_{2}$ to be included in the studies. Whereas Hwang et $\mathrm{al}^{24}$ applied a $25 \mathrm{~km}$ radius. The exposure assignments in the studies by Kim et $a l,{ }^{26}$ Pearce $e t a l^{25}$ and Vassilev et $a l^{32}$ were not based on any fixed radius. The two ecological studies ${ }^{30}{ }^{31}$ used annual mean concentrations of the pollutants studied to assign exposures.
Dimitriev $^{29}$ used monthly concentration of air pollutants in the study areas.

Six studies $\begin{array}{llllll}21 & 23 & 24 & 27 & 28 & 32\end{array}$ used a stillbirth cut-off point of $>20$ weeks of gestation, with three studies $22 \quad 2530$ using a cut-off of $>28$ weeks of gestation. Landgren ${ }^{33}$ and Sakai ${ }^{31}$ did not provide a case definition in their reports. DeFranco et al ${ }^{27}$ ascertained stillbirth by using both, last menstrual period (LMP) and ultrasound examination methods, whereas two other studies $^{25} 26$ mostly used the LMP method but also used fetal ultrasound examination if there was either uncertainty about the LMP date or discordance between the two estimates. Two studies $^{23} 28$ used the LMP method only, with Hwang et al ${ }^{24}$ applying ultrasound examination. The type of stillbirth studied was not mentioned in any of the included studies except the study by Pereira et al, ${ }^{22}$ which identified the stillbirths as intrauterine mortality, which we assume to be antepartum stillbirth. The source of data on stillbirth was obtained from fetal death certificates in five studies, ${ }^{21-23} 3233$ birth registry or vital statistics in five studies ${ }^{24} 2728 \quad 3031$ and hospital records in two studies. $^{25} 26$ Dimitriev $^{29}$ did not provide any information on how the stillbirths were ascertained.

\section{Methodological quality of the included studies Selection bias}

Selection bias was very minimal in the included studies as most of the studies collected data from fetal death certificates or birth 
registries and are likely to have represented their source populations with high response rate also reported. The prospective cohort study, ${ }^{26}$ however, only included pregnant women who visited the hospital for prenatal care, excluding mothers with missing values for residential address and sociodemographic risk factors. Few studies 252832 excluded mothers without gestational age information and census tract coding (8\%) from the analysis.

\section{Information bias}

There was evidence of potential information bias in all the included studies due to the reliance on proximity of maternal homes to the nearest air pollution monitoring station, ${ }^{21-31}$ and use of emission measurement and meteorological data ${ }^{32} 33$ in assessing exposure. Factors such as mother's mobility, change of residence during pregnancy, occupation of mother and air exchange were not considered, and this may lead to a decrease in the accuracy of the exposure assessment and introduce a nondifferential misclassification that might lead to an underestimation of the effects of air pollution. Also, the exposure source was not reported by the studies other than those by Hwang et $a l^{24}$ Pearce et al, ${ }^{25}$ Vassilev et $a l^{32}$ and Sakai. ${ }^{31}$ For the outcome measurement, the true dates of fetal death were unknown, hence an estimated time using date of delivery was recorded on the fetal death certificate and this may introduce bias. This was observed in the study by Faiz et al, ${ }^{21}{ }^{23}$ Hwang et $a l,{ }^{24} \mathrm{Kim}$ et $a l,{ }^{26}$ Green et al, ${ }^{28}$ Bobak and Leon, ${ }^{30}$ and Vassilev et al. ${ }^{32}$

\section{Control of confounding}

Any determinant of the risk of stillbirth could be considered as a potential confounder in cohort, case-control and crosssectional studies. The case-crossover study and time-series analyses eliminate any confounding related to individual characteristics and environmental exposures that are linked to the studied air pollutant. Most studies adjusted for the characteristics of the mother, such as age and family characteristics, at an individual level. Some of the studies applied control of confounding at group levels. ${ }^{30}$ When estimating the effect of an individual air pollutant, exposure to other air pollutants is a potential confounder. Only five studies fitted more than one air pollutant into the multivariate model, that is, applied multipollutant rather than single pollutant models. ${ }^{21} 22242830$

Regarding the ecological studies, Bobak and Leon $^{30}$ adjusted for several socioeconomic characteristics, which were obtained from the Czech Statistical office, at the district level; whereas Sakai ${ }^{31}$ did not control for confounding. In the time series analysis, Pereira et $a l^{22}$ adjusted for season and weather. Faiz et $a l^{21}$ conducted a case-crossover study where they controlled for mean temperature of the corresponding lag days. Of the nine long-term air pollution exposure studies, Dimitriev ${ }^{29}$ did not control for any confounding and the confounding control was considered inadequate in one study, ${ }^{33}$ as the author only adjusted for year of birth, maternal age and parity. Confounding control was considered adequate in the remaining studies. $^{23-28} 32$ These studies adjusted for a range of confounders including maternal age, race, education, socioeconomic status, season or month of conception, parity, infant sex, prenatal care and lifestyle characteristics. Hwang et $a l^{24}$ and Kim et $a l^{26}$ further controlled for gestational age and maternal anthropometry, respectively. Vassilev et al ${ }^{32}$ used separate Mantel-Haenzel OR analysis for potential confounding factors and few factors were controlled in the final logistic regression model, this approach can also be deemed as adequate control of confounding factors.

By applying the NOS scale, three studies 232428 were rated as very high quality (case-control/cohort -8 or more stars) and one study $^{26}$ was rated as high quality (cohort study -7 stars). The Newcastle-Ottawa-Scores for all the studies included in the meta-analyses are presented in the online supplementary table S2.

\section{Findings of included studies and summary effect estimates}

Summary effect estimates are presented in table 2 and the corresponding forest plot in figure 2 .

Three studies ${ }^{23} 2428$ provided estimates for the relation of $\mathrm{SO}_{2}$ exposure (per $3 \mathrm{ppb}, 1 \mathrm{ppb}$ and $10 \mathrm{ppb}$ increase in mean concentration) to stillbirth for the entire pregnancy period. The summary-effect estimate (EE) per 3 ppb increase in $\mathrm{SO}_{2}$ exposure in the random effects model was 1.022 (95\% CI 0.984 to $1.062)$, with low heterogeneity between the studies observed $\left(\mathrm{I}^{2}=19.6 \%\right)$. The case-crossover study ${ }^{21}$ reported increased risk of stillbirth with IQR (4.7 ppb) increase in mean $\mathrm{SO}_{2}$ exposure 2 days before delivery, and also found similar associations on all the lag days; whereas, another time series study ${ }^{22}$ reported marginal association between daily counts of intrauterine mortality and $\mathrm{SO}_{2}$ concentration on the same day as delivery. One of the ecological studies ${ }^{31}$ also found significant positive correlation between spontaneous fetal death rate and $\mathrm{SO}_{2}$ concentration. However, Landgren ${ }^{33}$ and other ecological study (per $50 \mu \mathrm{g} / \mathrm{m}^{3}$ increase in annual mean concentration of $\left.\mathrm{SO}_{2}\right),{ }^{30}$ however, did not find any association, even after adjustment with other pollutants SPM and $\mathrm{NO}_{\mathrm{x}}$.

Three studies $23 \quad 2428$ provided estimates for the relation of both $\mathrm{NO}_{2}$ and $\mathrm{CO}$ exposure for the entire pregnancy period, with the summary EE in the random effects model found to be 1.066 (95\% CI 0.965 to 1.178 ) per $10 \mathrm{ppb}$ increase in mean $\mathrm{NO}_{2}$ concentration and 1.025 (95\% CI 0.985 to 1.066$)$ per $0.4 \mathrm{ppm}$ increase in mean $\mathrm{CO}$ concentration, respectively. Evidence of high heterogeneity was observed in the $\mathrm{NO}_{2}$ analysis $\left(\mathrm{I}^{2}=79.6 \%\right)$. The case-crossover ${ }^{21}$ studies reported increased risk of stillbirth with IQR increase of $\mathrm{NO}_{2}(16.4 \mathrm{ppb})$ and $\mathrm{CO}(0.54 \mathrm{ppm})$ in mean concentration, respectively, 2 days before delivery and also found similar associations on all the lag days. The time-series study ${ }^{22}$ reported strong significant dose-response relationship between daily counts of intrauterine mortality with $\mathrm{NO}_{2}$ concentration, and marginal association with $\mathrm{CO}$ concentration at 5 days and 3 days before delivery, respectively. The findings of $\mathrm{CO}$ exposure with stillbirth were, however, less consistent. Sakai ${ }^{31}$ also found a statistically significant positive correlation between $\mathrm{NO}_{2}$ concentration and spontaneous fetal death rate. Pereira et $a l^{22}$ also developed an overall index of air pollution (combination of $\mathrm{NO}_{2}, \mathrm{SO}_{2}, \mathrm{CO}$ ) and found a very robust significant association with dose-response relationship, whereas Faiz et $a l^{21}$ used two pollutant models on lag day 2 but found estimates similar to those of the single pollutant models. Green et $a l^{28}$ adjusted $\mathrm{PM}_{2.5}$ or ozone with $\mathrm{NO}_{2}$ and the associations were unaffected.

Two studies ${ }^{24} 26$ provided estimates for the relation of stillbirth per $10 \mu \mathrm{g} / \mathrm{m}^{3}$ increase in average $\mathrm{PM}_{10}$ concentration during the entire pregnancy duration to the summary EE in the random effects model found to be 1.014 (95\% CI 0.948 to $1.085)$. Evidence of high heterogeneity was noted in the analysis $\left(\mathrm{I}^{2}=85.0 \%\right)$. The time series study ${ }^{22}$ did not find any statistically significant associations.

Two studies ${ }^{23} 28$ provided estimates for the relation of stillbirth per $4 \mu \mathrm{g} / \mathrm{m}^{3}$ increase in average $\mathrm{PM}_{2.5}$ concentration during the entire pregnancy duration to the summary EE in the 
Table 2 Summary effect estimates for the relation between ambient air pollution exposure and the risk of stillbirth

\begin{tabular}{|c|c|c|c|c|c|c|}
\hline \multirow[b]{2}{*}{ Air pollutant } & \multirow[b]{2}{*}{$\begin{array}{l}\text { Studies contributing to the } \\
\text { summary effect estimate }\end{array}$} & \multirow{2}{*}{$\begin{array}{l}\text { Fixed effects } \\
\text { Summary effect estimates } \\
\text { EE }(95 \% \mathrm{Cl})\end{array}$} & \multirow{2}{*}{$\begin{array}{l}\text { Random effects } \\
\text { Summary effect estimates } \\
\text { EE }(95 \% \mathrm{Cl})\end{array}$} & \multicolumn{3}{|c|}{ Heterogeneity } \\
\hline & & & & $\chi^{2}$ & $\mathrm{p}$ Value & $I^{2}(\%)$ \\
\hline $\mathrm{SO}_{2}(3 \mathrm{ppb})$ & Faiz 2012, Green 2015, Hwang 2011 & 1.019 (0.989 to 1.049$)$ & 1.022 (0.984 to 1.062$)$ & 2.49 & 0.288 & 19.6 \\
\hline 1st trimester & Faiz 2012, Green 2015, Hwang 2011, & $0.997(0.975$ to 1.020$)$ & 1.040 (0.962 to 1.125$)$ & 10.34 & 0.006 & 80.7 \\
\hline 2nd trimester & Faiz 2012, Green 2015, Hwang 2011 & $1.003(0.977$ to 1.030$)$ & $1.003(0.977$ to 1.030$)$ & 1.79 & 0.408 & 0.0 \\
\hline 3rd trimester & Faiz 2012, Green 2015, Hwang 2011 & $0.996(0.967$ to 1.026$)$ & $1.042(0.951$ to 1.142$)$ & 11.26 & 0.004 & 82.2 \\
\hline $\mathrm{NO}_{2}(10 \mathrm{ppb})$ & Faiz 2012, Green 2015, Hwang 2011 & 1.049 (1.012 to 1.088$)$ & 1.066 (0.965 to 1.178$)$ & 9.78 & 0.008 & 79.6 \\
\hline 1st trimester & Faiz 2012, Green 2015, Hwang 2011 & 1.025 (0.996 to 1.054$)$ & 1.035 (0.983 to 1.089$)$ & 4.43 & 0.109 & 54.8 \\
\hline 2nd trimester & Faiz 2012, Green 2015, Hwang 2011 & $1.005(0.977$ to 1.034$)$ & 1.007 (0.948 to 1.071$)$ & 5.83 & 0.054 & 65.7 \\
\hline 3rd trimester & Faiz 2012, Green 2015, Hwang 2011 & $1.015(0.980$ to 1.051$)$ & 1.015 (0.980 to 1.051$)$ & 1.88 & 0.391 & 0.0 \\
\hline CO $(0.4 \mathrm{ppm})$ & Faiz 2012, Green 2015, Hwang 2011 & 1.022 (0.995 to 1.050$)$ & 1.025 (0.985 to 1.066$)$ & 2.52 & 0.284 & 20.5 \\
\hline 1st trimester & Faiz 2012, Green 2015, Hwang 2011 & $1.002(0.983$ to 1.022$)$ & 1.011 (0.967 to 1.057$)$ & 2.92 & 0.232 & 31.6 \\
\hline 2nd trimester & Faiz 2012, Green 2015, Hwang 2011 & $1.002(0.979$ to 1.025$)$ & 1.015 (0.948 to 1.087$)$ & 5.60 & 0.061 & 64.3 \\
\hline 3rd trimester & Faiz 2012, Green 2015, Hwang 2011 & $1.014(0.992$ to 1.038$)$ & 1.052 (0.973 to 1.138$)$ & 10.19 & 0.006 & 80.4 \\
\hline $\mathrm{PM}_{10}\left(10 \mu \mathrm{g} / \mathrm{m}^{3}\right)$ & Hwang 2011, Kim 2007 & $1.012(0.986$ to 1.039$)$ & $1.014(0.948$ to 1.085$)$ & 6.67 & 0.010 & 85.0 \\
\hline 1st trimester & Hwang 2011, Kim 2007 & $1.015(0.991$ to 1.039$)$ & 0.998 (0.936 to 1.064$)$ & 2.18 & 0.140 & 54.1 \\
\hline 2nd trimester & Hwang 2011, Kim 2007 & 0.968 (0.944 to 0.993$)$ & 1.005 (0.905 to 1.116$)$ & 5.31 & 0.021 & 81.2 \\
\hline 3rd trimester & Hwang 2011, Kim 2007 & 0.995 (0.968 to 1.022$)$ & 1.021 (0.919 to 1.134$)$ & 10.96 & 0.001 & 90.9 \\
\hline $\mathrm{PM}_{2.5}\left(4 \mu \mathrm{g} / \mathrm{m}^{3}\right)$ & Faiz 2012, Green 2015 & 1.021 (0.996 to 1.046$)$ & 1.021 (0.996 to 1.046$)$ & 0.18 & 0.669 & 0.0 \\
\hline 1st trimester & Faiz 2012, Green 2015 & $1.002(0.982$ to 1.022$)$ & $1.042(0.920$ to 1.180$)$ & 2.35 & 0.126 & 57.4 \\
\hline 2nd trimester & Faiz 2012, Green 2015 & $1.011(0.996$ to 1.026$)$ & $1.040(0.940$ to 1.152$)$ & 1.92 & 0.166 & 47.9 \\
\hline 3rd trimester & Faiz 2012, Green 2015 & $1.00(0.981$ to 1.020$)$ & $1.00(0.981$ to 1.020$)$ & 0.23 & 0.631 & 0.0 \\
\hline $\mathrm{O}_{3}(10 \mathrm{ppb})$ & Green 2015, Hwang 2011 & $1.005(0.982$ to 1.029$)$ & 1.002 (0.971 to 1.034$)$ & 1.24 & 0.265 & 19.6 \\
\hline 1st trimester & Green 2015, Hwang 2011 & $1.001(0.983$ to 1.020$)$ & 1.001 (0.983 to 1.020$)$ & 0.13 & 0.714 & 0.0 \\
\hline 2nd trimester & Green 2015, Hwang 2011 & 1.004 (0.985 to 1.022$)$ & 0.991 (0.944 to 1.040$)$ & 3.18 & 0.074 & 68.6 \\
\hline 3rd trimester & Green 2015, Hwang 2011 & 1.025 (1.006 to 1.043$)$ & $1.012(0.966$ to 1.060$)$ & 2.72 & 0.099 & 63.2 \\
\hline
\end{tabular}

random effects model found to be 1.021 (95\% CI 0.996 to 1.046). No heterogeneity was noted in the analysis $\left(\mathrm{I}^{2}=0.0 \%\right)$. DeFranco et $^{\mathrm{al}} \mathrm{l}^{27}$ found non-significant $21 \%$ (OR: $1.21,95 \% \mathrm{CI}$ 0.96 to 1.53 ) increased risk in stillbirth with high $\mathrm{PM}_{2.5}$ $\left(15.67 \mu \mathrm{g} / \mathrm{m}^{3}\right)$ exposure during the entire pregnancy.

Two studies 24 provided estimates for the relation of stillbirth per $10 \mathrm{ppb}$ increase in average $\mathrm{O}_{3}$ concentration during the entire pregnancy duration to the summary $\mathrm{EE}$ in the random effects model found to be 1.002 (95\% CI 0.971 to 1.034). Evidence of low heterogeneity was noted in the analysis $\left(\mathrm{I}^{2}=19.6 \%\right)$. The time series study ${ }^{22}$ evaluated the relation between $\mathrm{O}_{3}$ exposure and stillbirth, and found no association.

Four studies ${ }^{23} 24 \quad 2628$ provided trimester-specific estimates for the relation of stillbirth risk to six pollutants $\left(\mathrm{SO}_{2}, \mathrm{NO}_{2}\right.$, $\mathrm{CO}, \mathrm{PM}_{10}, \mathrm{PM}_{2.5}, \mathrm{O}_{3}$ ). With the exception of $\mathrm{SO}_{2}$ exposure during the second trimester, $\mathrm{NO}_{2}$ and $\mathrm{PM}_{2.5}$ exposure during the third trimester and $\mathrm{O}_{3}$ exposure during the first trimester, we observed evidence of moderate to substantial heterogeneity in most of the analysis. In the random effect model, almost all these pollutants (per 3 ppb SO $2,10 \mathrm{ppb} \mathrm{NO}$, $0.4 \mathrm{ppm} \mathrm{CO}$, $10 \mu \mathrm{g} / \mathrm{m}^{3} \mathrm{PM}_{10}, 4 \mu \mathrm{g} / \mathrm{m}^{3} \mathrm{PM}_{2.5}$ and $10 \mathrm{ppb} \mathrm{O}_{3}$ increase in mean concentration) showed increased risk in each trimester except $\mathrm{SO}_{2}$ and $\mathrm{NO}_{2}$ exposure in the second trimester, $\mathrm{PM}_{10}$ and $\mathrm{O}_{3}$ exposure in the first and second trimester and $\mathrm{PM}_{2.5}$ exposure in the third trimester. For $\mathrm{SO}_{2}, \mathrm{CO}, \mathrm{PM}_{10}$ and $\mathrm{O}_{3}$, third trimester exposure appears to pose the highest risk whereas for $\mathrm{NO}_{2}$ and $\mathrm{PM}_{2.5}$, first trimester exposure posed the highest risk. The summary EE per $10 \mu \mathrm{g} / \mathrm{m}^{3}$ increase in $\mathrm{PM}_{10}$ exposure showed an increasing trend whereas for $\mathrm{PM}_{2.5}$ per $4 \mu \mathrm{g} / \mathrm{m}^{3}$ increase in concentration, a decreasing trend was observed. Regarding $\mathrm{SO}_{2}, \mathrm{NO}_{2}, \mathrm{CO}$ and $\mathrm{O}_{3}$, the trend was inconsistent with the second trimester summary estimates, being the lowest for $\mathrm{SO}_{2}, \mathrm{NO}_{2}, \mathrm{O}_{3}$ and first trimester for the $\mathrm{CO}$ exposure. Faiz et al found a non-significant small increased risk of stillbirth with IQR increase in the mean $\mathrm{PM}_{2.5}$ concentration in their time series analysis on all the lag days. Whereas DeFranco et $a l^{27}$ found significant $42 \%$ (OR 1.42, 95\% CI 1.06 to 1.91) increased risk in stillbirth with high $\mathrm{PM}_{2.5}\left(16.22 \mu \mathrm{g} / \mathrm{m}^{3}\right)$ exposure only in the third trimester. Hwang et $a l^{24}$ evaluated increased risk of stillbirth in association with $\mathrm{SO}_{2}$ per $1 \mathrm{ppb}$ and $\mathrm{PM}_{10}$ per $10 \mu \mathrm{g} / \mathrm{m}^{3}$ increase during the first and second months of pregnancy, and was stable after adjustment for $\mathrm{O}_{3}$ and either $\mathrm{CO}$ or $\mathrm{NO}_{2}$ in multipollutant models. Green et $a l^{28}$ found robust association with third trimester $\mathrm{O}_{3}$ exposure after addition of $\mathrm{PM}_{2.5}$ and $\mathrm{NO}_{2}$.

Dimitriev $^{29}$ compared the occurrence of stillbirth in good and worse ecological areas assessed on the basis of monthly concentration of selected pollutants (suspended solids, $\mathrm{SO}_{2}, \mathrm{CO}, \mathrm{NO}_{2}$ ), and reported risk of stillbirth as 6.63 and 11.03 per 1000 births, respectively. The estimated risk ratio showed a $65 \%$ (RR $1.650,95 \%$ CI 1.136 to 2.397 ) increased risk of stillbirth among mothers resident in polluted ecological areas.

Two studies ${ }^{313}$ that investigated the relation of NO exposure to stillbirth also found no association. The association between stillbirth risk and per $10 \mu \mathrm{g} / \mathrm{m}^{3}$ relating average weekly black smoke (equivalent to $\mathrm{PM}_{4}$ ) exposure was evaluated by Pearce et $a l,{ }^{25}$ but did not find any significant association during pregnancy. Bobak and Leon ${ }^{30}$ evaluated the effects of SPM and $\mathrm{NO}_{\mathrm{x}}$ (per $50 \mu \mathrm{g} / \mathrm{m}^{3}$ increase in concentration), and found no significant association in the single pollutant model nor after 

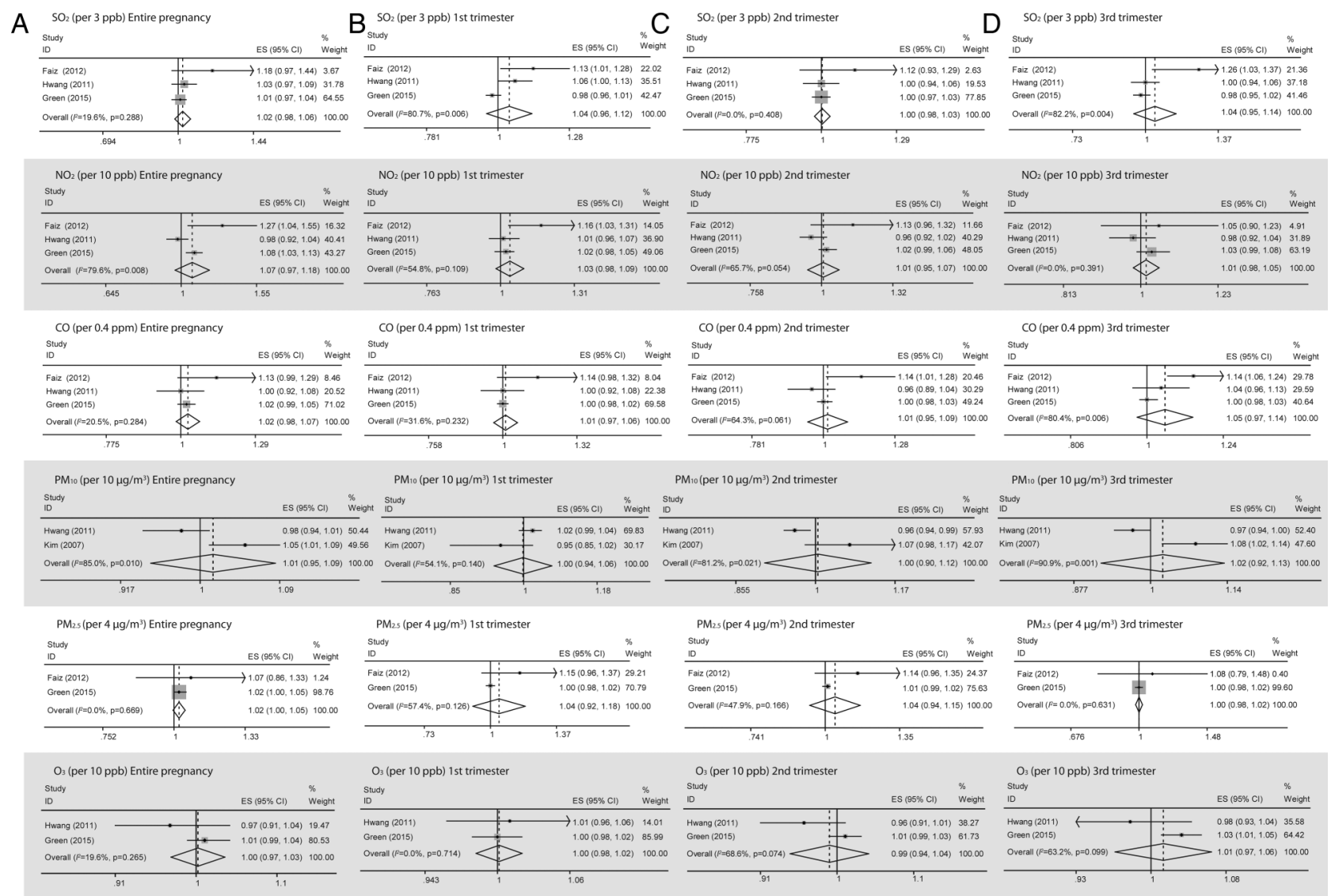

Figure 2 Forest plot showing the effect of ambient air pollutants on stillbirth. ES, effect size; weights are from random effects analysis.

adjustment with all pollutant ( $\mathrm{SPM}, \mathrm{SO}_{2}, \mathrm{NO}_{\mathbf{x}}$ ) models. Vassilev et $a l^{32}$ investigated POM exposure and, using low exposure as the reference category, found statistically significant increased risk of stillbirth with medium and high exposure (ORs of 1.21 (95\% CI 1.04 to 1.40 ) and 1.19 (95\% CI 1.02 to 1.39 ), respectively). The effect of $\mathrm{CH}$ was investigated by Landgren, ${ }^{33}$ but no association was found between stillbirth and levels of $\mathrm{CH}$ concentration in Swedish municipalities.

\section{Evaluation of publication bias}

Figure 3 presents the funnel plots for all the study specific effect estimates used to calculate the summary effect estimates. Online supplementary table S3 presents results from the Begg's and Egger's tests. There was no indication of publication bias present, although these results should be interpreted with caution because they were based on two or three study-specific effect estimates only.

\section{DISCUSSION}

Our systematic review and meta-analysis provided evidence that prenatal exposure to air pollution increases the risk of stillbirth. The summary effect estimates from the random effects models were systematically elevated, although they did not reach statistical significance. Per $10 \mathrm{ppb} \mathrm{NO}, 0.4 \mathrm{ppm} \mathrm{CO}, 3 \mathrm{ppb} \mathrm{SO} 2$, $4 \mu \mathrm{g} / \mathrm{m}^{3} \mathrm{PM}_{2.5}$ and $10 \mu \mathrm{g} / \mathrm{m}^{3} \mathrm{PM}_{10}$, increase in mean exposure during the entire pregnancy duration, respectively, resulted in a 6.6\% ( $\mathrm{EE}=1.066,95 \%$ CI 0.965 to 1.178$), 2.5 \%$ ( $\mathrm{EE}=1.025$, $95 \%$ CI 0.985 to 1.066$), 2.2 \%$ ( $\mathrm{EE}=1.022,95 \%$ CI 0.984 to 1.062), $2.1 \%$ ( $\mathrm{EE}=1.021,95 \%$ CI 0.996 to 1.046$)$ and $1.4 \%$ $(\mathrm{EE}=1.014,95 \% \mathrm{CI} 0.948$ to 1.085$)$ increased risk of stillbirth.
The point estimates for the third trimester were slightly elevated for $\mathrm{SO}_{2}, \mathrm{CO}, \mathrm{PM}_{10}$ and $\mathrm{O}_{3}$ consistently, with a hypothesis of a susceptible time window for the adverse effects, although the differences were not statistically significant. Two time series studies used lag day not more than 6 days preceding stillbirth and both found increased risk with certain pollutants.

\section{Validity of results}

We included all the studies identified in an extensive systematic search, so missing of important epidemiological studies is less likely to have happened. A significant number of studies have emerged since the last reviews; hence the critical assessment of the evidence is timely. Even though our review contains eight more studies and much more information than the previous reviews, we found a very limited number of estimates for each of the pollutants, and only five studies made attempts to adjust for other air pollutants when presenting effect estimates of each air pollutant. Therefore, we could not include all of the studies in the meta-analyses, and the reliability on the summary effect estimates is further compromised. However, the existing evidence is suggestive of causality for air pollution and stillbirth without precise identification of the timing of exposure. With the limited studies on the relevant topic, our review suggests strong priorities for future research. The visual inspection of the funnel plots and the statistical assessment did not indicate publication bias.

\section{Biological plausibility}

Fetuses are more affected by a variety of environmental toxicants because of differential exposure and physiological 
A $\mathrm{SO}_{2}$ Entire pregnancy

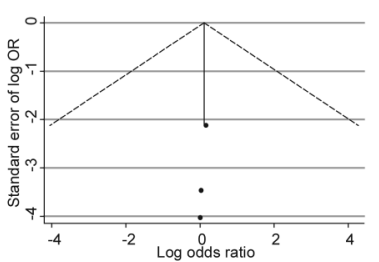

$\mathrm{NO}_{2}$ Entire pregnancy

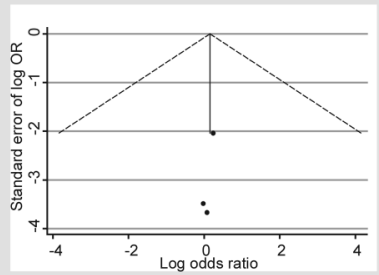

CO Entire pregnancy

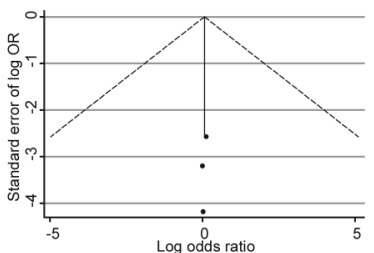

PM10 Entire pregnancy

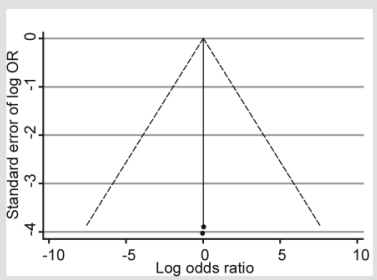

PM2.5 Entire pregnancy

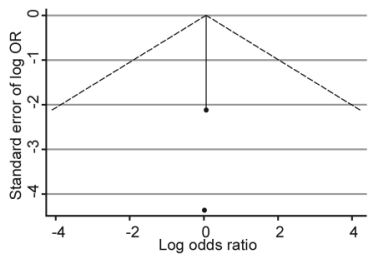

$\mathrm{O}_{3}$ Entire pregnancy

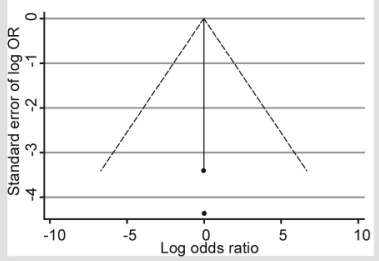

B $\mathrm{SO}_{2} 1$ st trimester

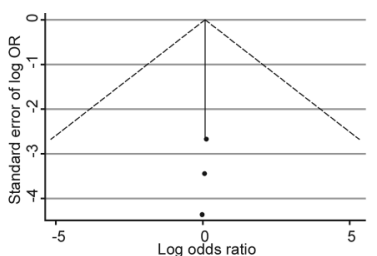

$\mathrm{NNO}_{2}$ 1st trimester

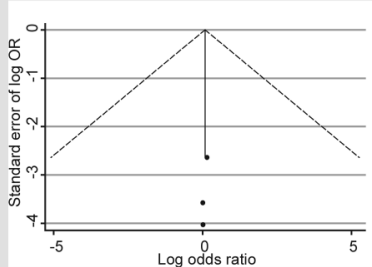

CO 1st trimester

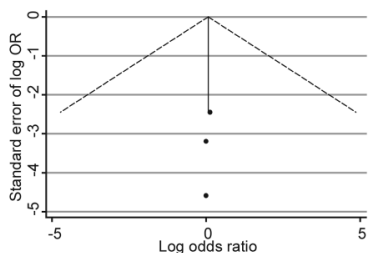

$\mathrm{PM}_{10}$ 1st trimeste

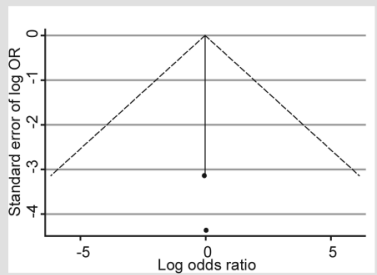

$\mathrm{PM}_{2.5}$ 1st trimester

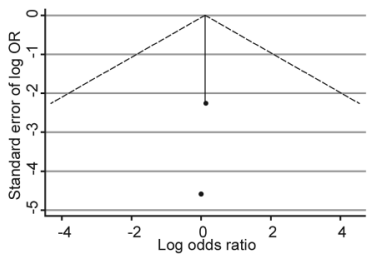

$\mathrm{O}_{3}$ 1st trimester

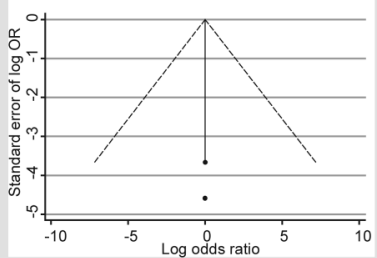

C $\mathrm{SO}_{2}$ 2nd trimester

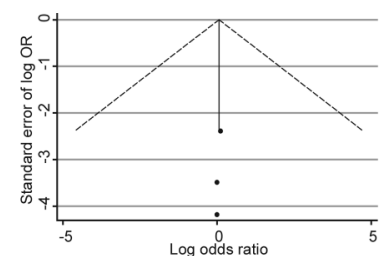

C. $\mathrm{NO}_{2} 2$ nd trimester

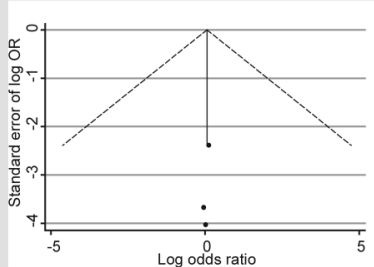

$\mathrm{CO}$ 2nd trimester

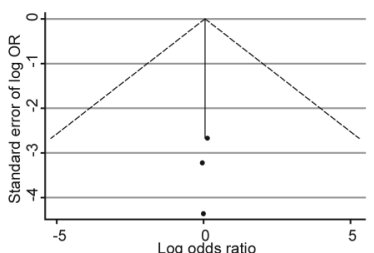

$\mathrm{PM}_{10}$ 2nd trimester

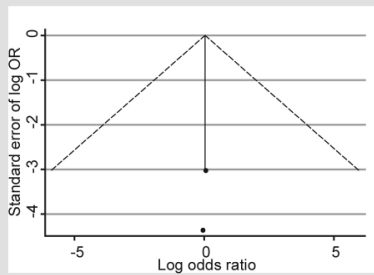

PM2.5 2nd trimester

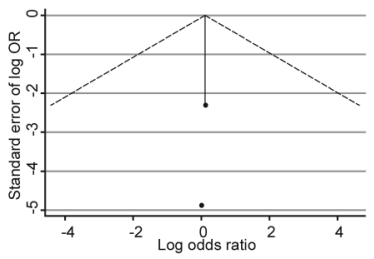

$\mathrm{O}_{3}$ 2nd trimester

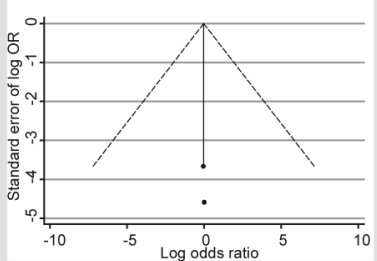

D $\mathrm{SO}_{2} 3$ rd trimester

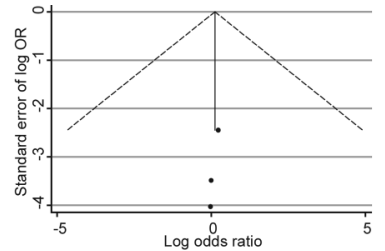

D. $\mathrm{NO}_{2} 3$ rd trimester

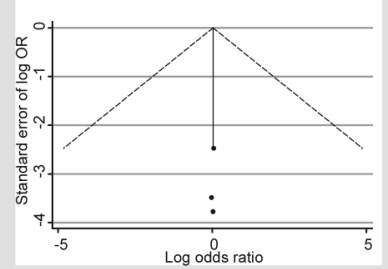

$\mathrm{CO}$ 3rd trimester

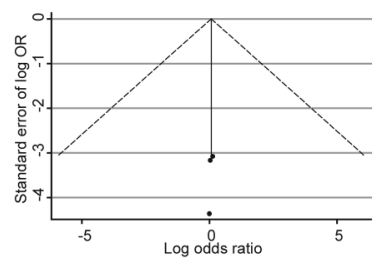

PM103rd trimester

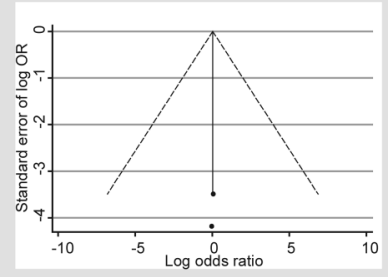

$\mathrm{PM}_{2.5}$ 3rd trimester

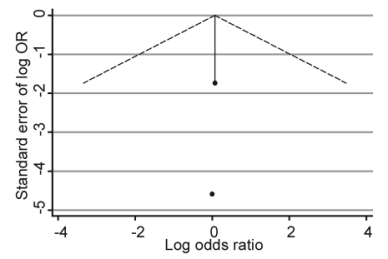

$\mathrm{O}_{3} 3$ rd trimester

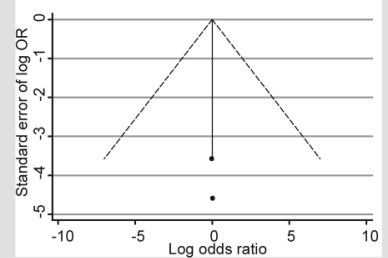

Figure 3 Funnel plot with pseudo 95\% confidence limits for the relation between ambient air pollutants and stillbirth. 
immaturity. ${ }^{34}$ The biological mechanisms by which exposure to ambient air pollutants leads to fetal death is not very clear. Faiz et $a l^{21}$ suggested the direct crossing of air pollutants across the placenta, causing irreversible damage to the dividing cells of the growing fetus and triggering hypoxic damage or immunemediated injury during critical periods of development, as a possible mechanism.

Of all the pollutants, only the mechanism of the toxic effects of $\mathrm{CO}$ on the fetus is well established. ${ }^{17} \mathrm{CO}$ reduces oxygencarrying capacity of maternal haemoglobin that could seriously affect oxygen delivery to fetal circulation. ${ }^{35}$ Sangalli et al $^{36}$ revealed that $\mathrm{CO}$ crosses the placental barrier and haemoglobin on fetal blood has greater affinity for binding $\mathrm{CO}$ than that in an adult; $\mathrm{O}_{2}$ delivery to fetal tissues is further compromised. ${ }^{37}$ Moreover, fetal elimination of carbon monoxide is slower than in the mother. ${ }^{38}$ There is also a significant dose-dependent relationship between $\mathrm{CO}$ and $\mathrm{COHb}$, and a developing fetus can be deprived of adequate oxygenation due to high levels of $\mathrm{COHb}$, which may even lead to fetal death. ${ }^{22}$

Maternal exposures to particulate (PM) air pollutants during pregnancy can result in increased concentration of DNA adducts or may lower the efficiency of the transplacental function, resulting in decreased fetal health leading to stillbirth. ${ }^{39} 40$

There is evidence that the presence of air pollution increases blood viscosity and plasma fibrinogen relates to coagulation; these haematological factors might have an influence on blood perfusion of the placenta, which could also lead to impair fetal health. ${ }^{41-43}$

\section{Synthesis with previous knowledge}

In the meta-analysis, we observed a 1.4\% (EE 1.014, 95\% CI 0.948 to 1.085 ) increased risk of stillbirth with $10 \mu \mathrm{g} / \mathrm{m}^{3}$ increase in $\mathrm{PM}_{10}$ exposure during the entire duration of pregnancy, albeit statistically but not significantly. Pereira et $a l^{22}$ also did not find any statistically significant association in their time series study. Glinianaia et al ${ }^{17}$ reported little evidence of association between exposure to PM and stillbirth risk, and thus describes it as insufficient to assess a possible association between PM and stillbirth.

For $\mathrm{PM}_{2.5}$, Zhu et al indicated that there was no evidence of statistically significant effect (OR: $1.18,95 \%$ CI 0.69 to 2.04 ) on stillbirth with an increase of $10 \mu \mathrm{g} / \mathrm{m}^{3}$; this result is consistent with our review, which reveals (EE 1.021, 95\% CI 0.996 to 1.046) with an increase of $4 \mu \mathrm{g} / \mathrm{m}^{3}$. However, in our meta-analysis, we also found a $4.2 \%$ (EE 1.042, 95\% CI 0.920 to 1.180 ) and $4.0 \%$ (EE $1.040,95 \%$ CI 0.940 to 1.152 ) increase per $4 \mu \mathrm{g} / \mathrm{m}^{3}$, in the first and second trimester, respectively.

We also observed a small and statistically non-significant increased risk of stillbirth with $\mathrm{SO}_{2} 2.2 \%$ (EE 1.022, 95\% CI 0.984 to 1.062 ) and $\mathrm{CO} 2.5 \%$ (EE 1.025 , 95\% CI 0.985 to 1.066) exposure for the entire pregnancy period in the meta-analysis. The short-term air pollution studies on these relationships $^{21}$ and one of the ecological studies ${ }^{31}$ also reported an increased risk of stillbirth related to $\mathrm{SO}_{2}$ and $\mathrm{CO}$ exposure. The findings of $\mathrm{CO}$ exposure with stillbirth was, however, less consistent.

Lacasana et $a l^{18}$ stated that $\mathrm{SO}_{2}$ and $\mathrm{CO}$ also showed some, though less consistent, relationship with intrauterine mortality. In our review, we found that there is an increased risk of stillbirth associated with increased ambient concentrations of sulfur dioxide in early pregnancy, with pooled effect estimates of $4.0 \%$ (EE $1.040,95 \%$ CI 0.962 to 1.125). Also, we found the highest pooled estimate of $5.2 \%$ (EE 1.052, 95\% CI 0.973 to 1.138 ) for carbon monoxide in the last trimester.

For $\mathrm{NO}_{2}$, we observed a higher increase risk of stillbirth of $6.6 \%$ (EE 1.066, 95\% CI 0.965 to 1.178 ) for the entire pregnancy. This finding is consistent with the study by Lacasana et $a l,{ }^{18}$ which reported an increased risk of stillbirth with exposure to $\mathrm{NO}_{2}$.

Most of the pollutants in polluted ambient air, such as PM and $\mathrm{CO}$, are also present in indoor air polluted by smoking and solid fuel combustion, although the concentrations are lower. Leonardi-Bee et $a l^{15}$ conducted a meta-analysis of studies on the effects of secondhand smoking on the risk of stillbirth, presenting a 23\% risk increase (EE 1.23, 95\% CI 1.09 to 1.38). Amegah et $a l^{16}$ synthesised the effect of solid fuels showing an effect estimate of $29 \%$ for stillbirth. These findings are consistent with the present pollutant-specific summary effect estimates and thus strengthen the hypothesis that ambient air pollution increases the risk of stillbirth.

\section{Conclusion, recommendations and implications for future research}

Our results provide suggestive evidence that ambient air pollution is a risk factor for stillbirth. Pregnant women should be aware of the potential adverse effects of ambient air pollution, although the prevention against exposure to air pollutants generally requires more action by the government than by the individual. The healthcare sector can create awareness and engage other sectors contributing to ambient air pollution (such as the housing sector, transportation sector, industries and the energy sector), to develop and implement policies such as control of vehicular emissions, fuel quality improvement and control of industrial waste emission, to reduce the risk of air pollutants.

Most of the studies reviewed used data from monitoring stations to assess maternal exposure levels. Future studies should integrate the use of personal monitoring methods and also consider the activity of mothers, change in residence, air exchange, mother's occupation and outdoor activities of the mothers. The pregnant women should also be monitored if possible from the first month of pregnancy in order to ascertain the exact period of the effect.

Acknowledgements The authors thank Svetlana Filatova, Medical Research Center Oulu, Oulu University Hospital and University of Oulu, Finland, for helping with the translation of the Russian study included in the review.

Contributors JJKJ conceived the study and designed it with AKA. NS and HAB conducted the search and screened the articles, and contributed to the statistical analyses. AKA contributed to the evaluation of the manuscript, writing of the manuscript, statistical analyses and interpretation of the results. All the authors revised the manuscript for important intellectual content, and the final version has been approved by all the authors. JJKJ takes responsibility for the integrity of the article.

Funding The University of Oulu strategic funds.

Competing interests None declared.

Provenance and peer review Not commissioned; externally peer reviewed.

Data sharing statement Data needed for repeating the meta-analyses are presented in tables. Additional information on the methods or preliminary data can be requested from the corresponding author.

\section{REFERENCES}

1 World Health Organization (WHO). Ambient (outdoor) air quality and health. http:/l www.who.int/mediacentre/factsheets/fs313/en/. Fact sheet N³13. Updated March, 2014.

2 Demetriou CA, Raaschou-Nielsen O, Loft S, et al. Biomarkers of ambient air pollution and lung cancer: a systematic review. Occup Environ Med 2012;69:619-27. 
3 Darrow LA, Klein M, Flanders WD, et al. Air pollution and acute respiratory infections among children 0-4 years of age: an 18-year time-series study. Am J Epidemiol 2014;180:968-77.

4 Lee BJ, Kim B, Lee K. Air pollution exposure and cardiovascular disease. Toxicol Res 2014;30:71-5. Review.

5 Bonzini M, Carugno M, Grillo $\mathrm{P}$, et al. Impact of ambient air pollution on birth outcomes: systematic review of the current evidences. Med Lav 2010;101:341-63.

6 Schikowski T, Adam M, Marcon A, et al. Association of ambient air pollution with the prevalence and incidence of COPD. Eur Respir J 2014;44:614-26.

7 Gowers AM, Cullinan P, Ayres JG, et al. Does outdoor air pollution induce new cases of asthma? Biological plausibility and evidence; a review evidence; a review. Respirology 2012;17:887-98.

8 World Health Organization (WHO). Burden of disease from ambient air pollution for 2012. Geneva: WHO, 2014. http://www.who.int/phe/health_topics/outdoorair/ databases/FINAL_HAP_AAP_BoD_24March2014.pdf. (accessed 14 Nov 2014)

9 Sapkota A, Chelikowsky AP, Nachman KE, et al. Exposure to particulate matter and adverse birth outcomes: a comprehensive review and meta-analysis. Air Qual Atmos Health 2012;5:369-81.

10 Maisonet M, Correa A, Misra D, et al. A review of the literature on the effects of ambient air pollution on fetal growth. Environ Res 2004;95:106-15.

11 Vrijheid M, Martinez D, Manzanares S, et al. Ambient air pollution and risk of congenital anomalies: a systematic review and meta-analysis. Environ Health Perspect 2011;119:598-606.

12 Stillerman KP, Mattison DR, Giudice LC, et al. Environmental exposures and adverse pregnancy outcomes: a review of the science. Reprod Sci 2008;15:631-50.

13 Cousens $\mathrm{S}$, Blencowe $\mathrm{H}$, Stanton $\mathrm{C}$, et al. National, regional, and worldwide estimates of stillbirth rates in 2009 with trends since 1995: a systematic analysis. Lancet 2011;377:1319-30.

14 Aminu $M$, Unkels R, Mdegela $M$, et al. Causes of and factors associated with stillbirth in low- and middle-income countries: a systematic literature review. BJOG 2014;121(Suppl 4):141-53.

15 Leonardi-Bee J, Britton J, Venn A. Secondhand smoke and adverse fetal outcomes in nonsmoking pregnant women: a meta-analysis. Pediatrics 2011;127:734-41.

16 Amegah AK, Quansah R, Jaakkola JJ. Household air pollution from solid fuel use and risk of adverse pregnancy outcomes: a systematic review and meta-analysis of the empirical evidence. PLOS ONE 2014;9:e113920.

17 Glinianaia SV, Rankin J, Bell R, et al. Particulate air pollution and fetal health: a systematic review of the epidemiologic evidence. Epidemiology 2004;15:36-45.

18 Lacasaña M, Esplugues A, Ballester F. Exposure to ambient air pollution and prenatal and early childhood health effects. Eur J Epidemiol 2005;20:183-99.

19 Zhu X, Liu Y, Chen Y, et al. Maternal exposure of fine particulate matter $\left(\mathrm{PM}_{2.5}\right)$ and pregnancy outcomes: a meta-analysis. Environ Sci Pollut Res 2015;22:3383-96.

20 Wells G, Shea B, O'Connell D, et al. The Newcastle-Ottawa Scale (NOS) for assessing the quality if nonrandomized studies in meta-analyses. http://www.ohri.ca/ programs/clinical_epidemiology/oxford.htm. (accessed 22 Feb 2013)

21 Faiz AS, Rhoads GG, Demissie K, et al. Does ambient air pollution trigger stillbirth? Epidemiology 2013;24:538-44.

22 Pereira LA, Loomis D, Conceicão GM, et al. Association between air pollution and intrauterine mortality in Sao Paulo, Brazil. Environ Health Perspect 1998;106:325-9.
23 Faiz AS, Rhoads GG, Demissie K, et al. Ambient air pollution and the risk of stillbirth. Am J Epidemiol 2012;176:308-16.

24 Hwang BF, Lee YL, Jaakkola JJ. Air pollution and stillbirth: a population-based case-control study in Taiwan. Environ Health Perspect 2011;119:1345-9.

25 Pearce MS, Glinianaia SV, Rankin J, et al. No association between ambient particulate matter exposure during pregnancy and stillbirth risk in the north of England, 1962-1992. Environ Res 2010;110:118-22.

26 Kim OJ, Ha EH, Kim BM, et al. PM10 and pregnancy outcomes: a hospital-based cohort study of pregnant women in Seoul. J Occup Environ Med 2007;49:1394-402.

27 DeFranco $E$, Hall $E$, Hossain $M$, et al. Air pollution and stillbirth risk: exposure to airborne particulate matter during pregnancy is associated with fetal death. PLOS ONE 2015;10:e0120594.

28 Green R, Sarovar V, Malig B, et al. Association of stillbirth with ambient air pollution in a California cohort study. Am J Epidemiol 2015;181:874-82.

29 Dimitriev DA. Effects of air pollution on stillbirth in an industrial town. Gig Sanit 2000;5:7-9.

30 Bobak M, Leon DA. Pregnancy outcomes and outdoor air pollution: an ecological study in districts of the Czech Republic 1986-8. Occup Environ Med 1999;56:539-43

31 Sakai R. Fetal abnormality in a Japanese industrial zone. Int J Environ Stud 2007;23:113-20

32 Vassilev ZP, LRobson MG, Klotz JB. Outdoor exposure to airborne polycyclic organic matter and adverse reproductive outcomes: a pilot study. Am J Ind Med 2001;40:255-62.

33 Landgren 0 . Environmental pollution and delivery outcome in southern Sweden: a study with central registries. Acta Paediatr 1996;85:1361-4.

34 Perera FP, Jedrychowski W, Rauh V, et al. Molecular epidemiologic research on the effects of environmental pollutants on the fetus. Environ Health Perspect 1999;107:451-60.

35 Salam MT, Millstein J, Li YF, et al. Birth outcomes and prenatal exposure to ozone, carbon monoxide, and particulate matter: results from the Children's health study. Environ Health Perspect 2005;113:1638-44.

36 Sangalli MR, Mclean AJ, Peek MJ, et al. Carbon monoxide disposition and permeability-surface area product in the foetal circulation of the perfused term human placenta. Placenta 2003;24:8-11.

37 Di Cera E, Doyle ML, Morgan MS, et al. Carbon monoxide and oxygen binding to human hemoglobin F0. Biochemistry 1989;28:2631-8.

38 Hill EP, Hill JR, Power GG, et al. Carbon monoxide exchanges between the human fetus and mother: a mathematical model. Am J Physiol 1977;232:H311-23.

39 Perera FP, Hemminki K, Gryzbowska $E$, et al. Molecular and genetic damage in humans from environmental pollution in Poland. Nature 1992;360:256-8.

40 Zondervan HA, Oosting J, Hardeman MR, et al. The influence of maternal whole blood viscosity on fetal growth. Eur J Obstet Gynecol Reprod Biol 1987;25:187-94.

$41 \mathrm{Ha}$ EH, Kwon HJ. Issues in air pollution epidemiologic studies. Korean J Pre Med 2001;34:109-18.

42 Peters A, Döring A, Wichmann HE, et al. Increased plasma viscosity during an air pollution episodes: a link to mortality? Lancet 1997;349:1582-7.

43 Knottnerus JA, Delgado LR, Knipschild PG, et al. Haematological parameters and pregnancy outcome. A prospective cohort study in the third trimester. J Clin Epidemiol 1990;43:461-6. 